\title{
Theoretical Study of Tautomeric Equilibrium, the Stability, Polarizability, HOMO-LUMO Analysis and Acidity of 4,4-diméthyl-3,4-dihydroquinolin-2(1H)-one Derivatives
}

\author{
Lucie Affoue Bede*, Benjamine Amon Assoma, Latyfatou Laye Alao, Denis Kicho Yapo, \\ Soleymane Kone
}

Unit of Formation and Research of Sciences of Structures of Matter and Technology (UFR SSMT), University Felix Houphouët-Boigny, Abidjan, Ivory Coast

\section{Email address:}

lucie.bede@univ-fhb.edu.ci (L. A. Bede)

*Corresponding author

\section{To cite this article:}

Lucie Affoue Bede, Benjamine Amon Assoma, Latyfatou Laye Alao, Denis Kicho Yapo, Soleymane Kone. Theoretical Study of Tautomeric Equilibrium, the Stability, Polarizability, HOMO-LUMO Analysis and Acidity of 4,4-diméthyl-3,4-dihydroquinolin-2(1H)-one Derivatives. International Journal of Computational and Theoretical Chemistry. Vol. 7, No. 2, 2019, pp. 107-114. doi: 10.11648/j.ijctc.20190702.11

Received: August 13, 2019; Accepted: August 28, 2019; Published: September 11, 2019

\begin{abstract}
Quinoline derivatives have several reactionnels sites conferring them a hight reactivity. This makes them excellent precursors in the synthesis of new bioactive compounds. Considering the interest of quinoline chemistry and diversity of their applications, a study based on a theoretical approach of reactivity of 4,4-dimethyl-3,4-dihydro-quinolin-2(1H)-one and derivatives is carried. This study determines interaction sites of these derivatives in order to understand the mechanisms involved. Calculations are carried in gaseous phase and solution in N, N-dimethylformamide (DMF). Density Functional Theory (DFT/B3LYP) method associated with 6-311G(d) and 6-311+G (d) bases is used to perform these calculations. Results of the thermodynamic parameters showed that there is a tautomeric equilibrium relationship between the different derivatives Reactivity analysis based on Frontier Molecular Orbitals theory revealed that tautomers ketone are less reactive than tautomers enol. Calculation of Fukui indices indicates that the carbon atoms $\mathrm{C}^{2}, \mathrm{C}^{3}, \mathrm{C}^{5}, \mathrm{C}^{7}$ and $\mathrm{C}^{8}$ of quinoline-2-one ring are sites favorable to nucleophilic attack. Atoms $\mathrm{N}^{1}, \mathrm{C}^{4}, \mathrm{C}^{6}$ and $\mathrm{O}^{11}$ are nucleophilic sites therefore favorable to an electrophilic attack. Methoxyl substituent $\left(\mathrm{CH}_{3} \mathrm{O}\right)$ decreases the acidity of nitrogen and oxygen atoms of quinolin-2-one while bromine atom increases acidity of these same sites. These results predict a deprotonation of the nitrogen $\left(\mathrm{N}^{1}\right)$ of the brominated quinoline-2ones less energetic than that of the methoxylated derivatives. Conclusively, this work provides data to elucidate the mechanisms to understand the reactivity of 4,4-diméthyl-3,4-dihydroquinolin-2(1H)-one derivatives.
\end{abstract}

Keywords: DihydroQuinolin-2-one, Equilibrium Constant, HOMO, LUMO, Fukui Indices

\section{Introduction}

Quinolines are heterocyclic alkaloids. These heterocycles are important synthetic targets for the pharmaceutical industry as well as academic laboratories because of their rich chemistry and numerous applications [1-4]. It should be noted that these compunds have several reactionnels sites their conferring hight reactivity $[3,4]$. These derivatives are excellent precursors in synthesis of new heterocyclics which have interesting biological properties relating to treatment certain diseases such as malaria [5], tuberculosis [6, 7], antibacterienx [8, 9], antiprotozoal agents [10], anti-tumor
[11], anti-inflammatory [12].

Given interest of quinoline chemistry and diversity of their applications, a study based on a theoretical approach of reactivity of 4,4-dimethyl-3,4-dihydro-quinolin-2(1H)-one and derivatives is carried out. Previous theoretical work has shown influence of substituents on reactivity of quinoline-4one derivatives [13]. Present study determines the sites of interaction of 4,4-dimethyl-3,4-dihydroquinolin-2-one derivatives. Due to their tautomerism to 2-hydroxyquinolines (Figure 1), a study of reaction mechanism and stability of tautomers of 4,4-dimethyl-3,4-dihydroquinolin-2-one derivatives is carried. A prediction of acidity of tautomers is 
made from calculations of Gibbs free energies of deprotonation. Analysis of the HOMO and LUMO orbitals is carried using the theory of frontier molecular orbitals. Calculations are performed in gas phase and solution in N,NDimethylformamide (DMF) with method of Density Functional Theory (DFT). Thermodynamic energies, equilibrium constants and reactivity parameters are determined. Calculation of activation energies and determination of reaction path by the application of Intrinsic Reaction Reaction (IRC) method made it to analyze the reaction mechanism of tautomeric equilibrium reaction. Molecular structures of tautomers of 4,4-dimethyl-3,4dihydroquinolin-2 (1H)-one derivatives studied are represented in figure 2.
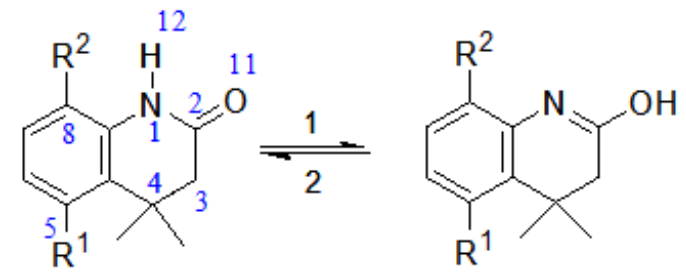

Figure 1. Tautomeric quilibrium bandween the tautomers ketone and enol.<smiles>CC1(C)CC(=O)Nc2cccc(O)c21</smiles><smiles>COc1ccc(OC)c2c1NC(=O)CC2(C)C</smiles><smiles>CC1(C)CC(=O)Nc2c(Br)ccc(Br)c21</smiles><smiles>CC1(C)CC(O)=Nc2ccccc21</smiles><smiles>COc1ccc(OC)c2c1N=C(O)CC2(O)OCO</smiles><smiles>CC1(C)CC(O)=Nc2c(Br)ccc(Br)c21</smiles>

Figure 2. Structures of tautomers of 4,4-diméthyl-3,4-dihydroquinolin2(1H)-one derivatives.

\section{Computational Details}

All calculations were performed by Density Functional Theory (DFT) method using Gaussian 03 program [14]. Geometry optimization of all structures, i.e., tautomers and transition state (TS), was carried out at DFT/B3LYP level of theory [15] using 6-311G(d,p) and 6-311+G(d,p) basis. Calculations are carried gas phase and solution. N,NDimethylformamide (DMF) being one of solvents used for synthesis of these quinolines [16], calculations in solution are thus carried out in this solvent. Solvation effects were taken into account using conductor like polarizable continuum (CPCM) model implemented in Gaussian code. This theoretical study is carried out at the temperature of $298 \mathrm{~K}$. All optimized geometries were characterized by vibrational analysis in the harmonic approximation, with no imaginary frequency. Moreover, the transition state (TS) structures were optimized and were characterized and confirmed by frequency calculations to ensure that they were first order saddle point with only one imaginary frequency mode and intrinsic reaction coordinate (IRC) calculations [17]. Global indices have been calculated using frontier densities, frontier energies and local indices through atomic populations as an approximate form of their expression from the system density.

\section{Results and Discussion}

\subsection{Thermodynamic Parameters and Relative Stability}

Calculated thermodynamic parameters are free enthalpies and enthalpies of formation. From these thermodynamic quantities, reaction enthalpies and equilibrium constants are determined. The order of relative stability of the tautomers is established from the enthalpy energies of formation of the different compounds. The values of the thermodynamic parameters calculated in gas phase and solution in DMF solvent are reported in table 1 .

Table 1. Enthalpy of formation (ua), reaction enthalpy ( $\mathrm{kcal} / \mathrm{mol}$ ) and equilibrium constants of tautomers of quinoline derivatives calculated at B3LYP/6-311G (d) level.

\begin{tabular}{|c|c|c|c|c|c|c|c|}
\hline Tautomers & $\Delta_{\mathrm{f}} \mathrm{H}(\mathrm{ua})$ & $\Delta_{\mathrm{f}} \mathbf{G}(\mathrm{ua})$ & Equillibrium & $\Delta_{\mathrm{r}} \mathrm{H}$ & $\Delta_{\mathrm{r}} \mathbf{G}$ & $K_{\text {eq1 }}$ & $K_{\text {eq2 }}$ \\
\hline \multicolumn{8}{|l|}{ Gas phase } \\
\hline DdQ-1 & -556.901413 & -556.949712 & \multirow{2}{*}{ DdQ-1↔DdQ-1-ol } & \multirow{2}{*}{13.63} & \multirow{2}{*}{13.83} & \multirow{2}{*}{$9.4 .10^{-3}$} & \multirow{2}{*}{$8.1 .10^{2}$} \\
\hline DdQ-1-ol & -556.879691 & -556.927671 & & & & & \\
\hline DdQ-2 & -785.926757 & -785.987421 & \multirow{2}{*}{ DdQ-2↔DdQ-2-ol } & \multirow{2}{*}{17.13} & \multirow{2}{*}{17.32} & \multirow{2}{*}{$6.9 .10^{-3}$} & \multirow{2}{*}{$5.5 .10^{2}$} \\
\hline DdQ-2-ol & -785.899463 & -785.959826 & & & & & \\
\hline DdQ-3 & -5703.991709 & -5704.049618 & \multirow{2}{*}{ DdQ-3↔DdQ-3-ol } & \multirow{2}{*}{13.32} & \multirow{2}{*}{13.57} & \multirow{2}{*}{$3.3 .10^{-3}$} & \multirow{2}{*}{$2.1 .10^{2}$} \\
\hline DdQ-3-ol & -5703.970475 & -5704.027998 & & & & & \\
\hline DdQ-1 & -556.896726 & -556.969271 & \multirow{2}{*}{ DdQ-1↔DdQ-1-ol } & \multirow{2}{*}{11.49} & \multirow{2}{*}{10.16} & \multirow{2}{*}{$8.4 .10^{-3}$} & \multirow{2}{*}{$1.20 .10^{2}$} \\
\hline DdQ-1-ol & -556.878413 & -556.953079 & & & & & \\
\hline DdQ-2 & -785.926189 & -786.021582 & \multirow{2}{*}{ DdQ-2↔DdQ-2-ol } & \multirow{2}{*}{17.23} & \multirow{2}{*}{13.06} & \multirow{2}{*}{$9.3 .10^{-3}$} & \multirow{2}{*}{$1.41 .10^{2}$} \\
\hline DdQ-2-ol & -785.898731 & -786.000767 & & & & & \\
\hline DdQ-3 & -5703.989986 & -5704.079431 & \multirow{2}{*}{ DdQ-3↔DdQ-3-ol } & \multirow{2}{*}{7.08} & \multirow{2}{*}{12.64} & \multirow{2}{*}{$4.5 .10^{-3}$} & \multirow{2}{*}{$1.2 .10^{2}$} \\
\hline DdQ-3-ol & -5703.978705 & -5704.059282 & & & & & \\
\hline
\end{tabular}

An equilibrium betwen compounds $\mathrm{A}$ and $\mathrm{B}$ is characterized by its equilibrium constant $\mathrm{K}_{\mathrm{eq}}$.

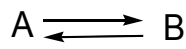

Calculation of $\mathrm{K}_{\mathrm{eq}}$ makes it possible to highlight existence tautomeric equilibrium. $\mathrm{K}_{\mathrm{eq}}$ 's values are obtained at $298 \mathrm{~K}$ with the relation: 


$$
K_{e q}=\exp \left(-\Delta_{r} G(T) / R T\right)
$$

When $\mathrm{K}_{\mathrm{eq}}<10^{-4}$, the form $\mathrm{A}$ exists alone. If $\mathrm{K}_{\mathrm{eq}}>10^{4}$, compound $\mathrm{B}$ predominates. The equilibrium becomes effective if $\mathrm{K}_{\mathrm{eq}}$ ranging from $10^{-4}$ to $10^{4}$.

$\mathrm{K}_{\mathrm{eq} 1}$ and $\mathrm{K}_{\mathrm{eq} 2}$ are respectively equilibrium constants in directions 1 and 2 (Figure 1). Values of equilibrium constants calculated for these derivatives are bandween $10^{-4}$ and $10^{4}$ (Table 1). This indicates that the studied systems are in a tautomeric equilibrium state. These molecules can exist under tautomers. For two given tautomers, the results show that the ketone forms (DdQ-1, DdQ-2, DdQ-3) have the lowest formation enthalpy values (Table 1). These are therefore more stable than tautomrs enol. Valeurs of reaction enthalpies energies are all positive. Tautomeric equilibrium of these derivatives is endothermic and non-spontaneous reaction at the temperature of $298 \mathrm{~K}$.

\subsection{Reaction Mechanism}

Theory of Transition States (TST) [18] and determination of the reaction path by the application of the Intrinsic Return Coordinate (IRC) method [17] are two approaches often used to study the reaction mechanism.

\subsubsection{Transition State Theory (TST)}

According to theory of transition state, passage from reagents to products requires a transition state; that is crossing over of an activation energy barrier $E a$ which is calculated from the following relation:

$$
\begin{gathered}
E_{a}=E_{(T S)}-E_{(\text {reagents })} \\
E_{a 1}=E_{(T S)}-E_{(\text {tautomer ketone })} \\
E_{a 2}=E_{(T S)}-E_{(\text {tautomer enol })}
\end{gathered}
$$

Values of calculated activation energies at B3LYP/6$311 \mathrm{G}(\mathrm{d}, \mathrm{p})$ level in gas phase, are mentioned in figure 3 . Structures of transition states are represented in figure 4.

Each chemical reaction is linked to a characteristic duration, determined from the length of energy barrier Ea to be crossed. The higher the barrier, the longer this characteristic duration is, the slower the chemical system transformation is. Energies $E a_{1}$ and $E a_{2}$ are respectively barriers to be crossed in order to go from tautomer ketone to tautomer enol (ketone $\rightarrow$ enol) and for passe from enol to ketone (ketone $\leftarrow$ enol). All energies $E a_{l}$ barriers are higher than energies $E a_{2}$. The difference between these two energy barriers $\left(E a_{1}\right.$ and $\left.E a_{2}\right)$ varies from $7.2 \mathrm{kcal} / \mathrm{mol}$ to 5.9 $\mathrm{kcal} / \mathrm{mol}$. The largest difference is obtained with tautomers of derivative DdQ- 1 and the small difference is obtained with tautomers of derivative DdQ-3. These values show that passage from tautomer ketone to tautomer enol requires much more energy. These results confirm stability of tautomers ketone with respect to tautomers enol. They therefore indicate a predominance of tautomer ketone in reaction medium. Values of energies $\mathrm{Ea}_{1}$ and $\mathrm{Ea}_{2}$ decrease with substitution. This variation is greater with bromine atom
(Br). Methoxyl group causes a smaller variation. This leads us to conclude that electron-withdrawing substituents at positions 5 and 8 of 4,4-dimethyl-3,4-dihydroquinoline-2-one help to promote tautomeric equilibrium in these derivatives.

\subsubsection{Determination of Reaction Path}

Determination of a transition state can be followed by an Intrinsic Reaction Coordinate (IRC) calculation. Reaction path of reaction is determined and transition state is connected to both minima (tautomer ketone and tautomer enol). From these different reaction paths, Complete optimization of the two extreme structures leads either to tautomer ketone or to tautomer enol. This result indicates nonexistence of an intermediate reaction product. For all derivatives studied, reaction pathways reveal stability of tautomers ketone with respect to tautomers enol.
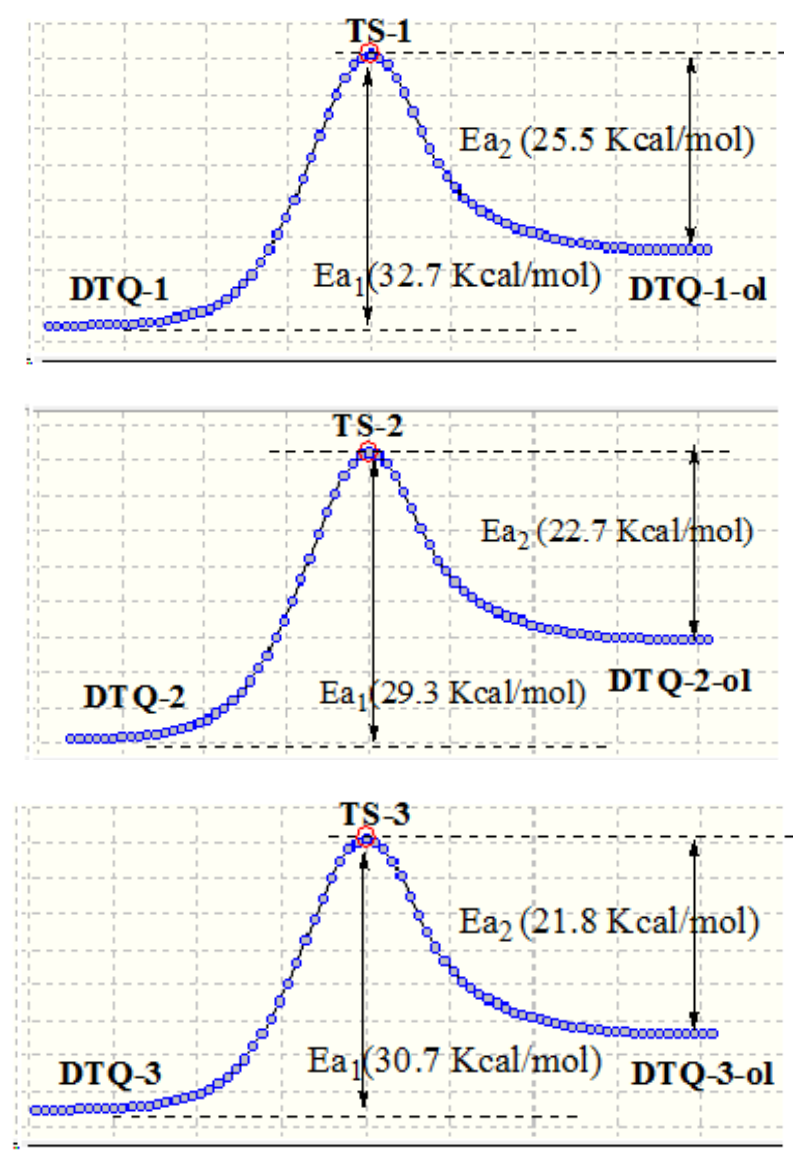

Figure 3. Global Intrinsic Reaction Coordinate (IRC) of tautomeric equilibrium calculated at B3LYP/6-311G(d,p) level.

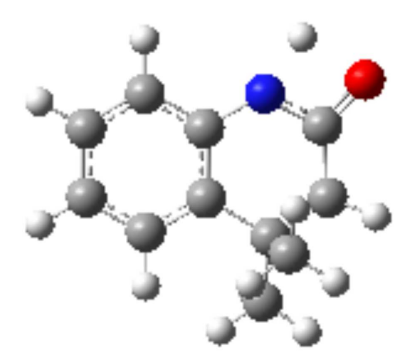

(a) 


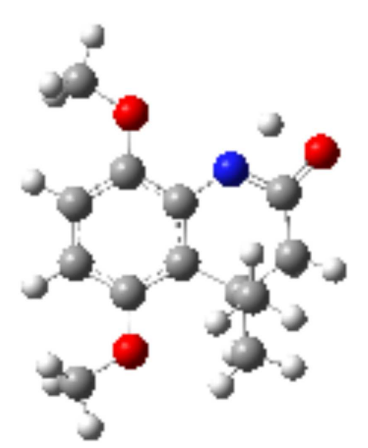

(b)

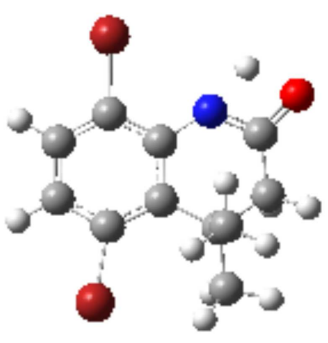

(c)

Figure 4. Theoretical geometric structures of transition states (a): TS1, (b): TS2, (c): TS3.

\subsection{Geometric Parameters}

Geometric parameters of optimized geometries of tautomers ketone and transition states are listed in Table 2. This analysis relates to distances between bonded atoms and valence angles formed by three bonded atoms of quinoline-2one cycle. Numbers of atoms are given in figure 1 .

Table 2. Geometric parameters for quinoline derivatives and transition states Calculated at B3LYP/6-311G(d,p) level.

\begin{tabular}{lclllll}
\hline \multirow{2}{*}{$\begin{array}{l}\text { Parameters } \\
\text { geometric }\end{array}$} & \multicolumn{2}{c}{ Tautomers ketone } & \multicolumn{4}{c}{ Transition state (TS) } \\
\cline { 2 - 7 } BTQ-1 & DTQ-2 & DTQ-3 & TS1 & TS2 & TS3 \\
Bond lengths $(\AA)$ & & & & & & \\
C2-C2 & 1.36 & 1.36 & 1.37 & 1.31 & 1.31 & 1.31 \\
C2-C3 & 1.23 & 1.22 & 1.22 & 1.28 & 1.28 & 1.28 \\
C3-C4 & 1.51 & 1.51 & 1.50 & 1.49 & 1.48 & 1.48 \\
C4-C9 & 1.56 & 1.55 & 1.55 & 1.55 & 1.56 & 1.56 \\
C5=C9 & 1.53 & 1.54 & 1.55 & 1.54 & 1.55 & 1.56 \\
C5-C6 & 1.40 & 1.40 & 1.40 & 1.39 & 1.41 & 1.40 \\
C6-C7 & 1.40 & 1.41 & 1.40 & 1.40 & 1.39 & 1.40 \\
C7=C8 & 1.39 & 1.39 & 1.38 & 1.39 & 1.40 & 1.38 \\
C8-C9 & 1.39 & 1.38 & 1.40 & 1.40 & 1.41 & 1.40 \\
C9=C10 & 1.40 & 1.41 & 1.42 & 1.42 & 1.41 & 1.43 \\
N1-H12 & 1.01 & 1.01 & 1.01 & 1.36 & 1.36 & 1.35 \\
O11-H12 & 2.45 & 2.48 & 2.48 & 1.34 & 1.34 & 1.33 \\
Valence angles & $\left.{ }^{\circ}\right)$ & & & & & \\
N1-C2-O11 & 121.3 & 122.1 & 121.7 & 108.4 & 108.3 & 108.2 \\
C9-N1-C2 & 126.5 & 125.4 & 125.8 & 122.7 & 123.1 & 123.7 \\
N1-C2-C3 & 117.3 & 115.7 & 115.3 & 122.7 & 122.2 & 121.7 \\
C2-C3-C4 & 120.6 & 118.2 & 118.3 & 110.8 & 112.4 & 112.0 \\
C3C4C10 & 112.9 & 109.2 & 109.0 & 109.8 & 110.7 & 110.7 \\
C10C5C6 & 122.2 & 120.7 & 123.1 & 121.6 & 120.8 & 122.9 \\
C5C6C7 & 119.5 & 120.8 & 120.0 & 119.8 & 120.8 & 120.2 \\
C6C7C8 & 119.6 & 119.8 & 118.9 & 120.0 & 120.1 & 119.1 \\
C7C8C9 & 120.4 & 119.3 & 121.4 & 120.1 & 119.1 & 121.1 \\
N1-H12-O11 & 67.7 & 65.6 & 66.9 & 102.4 & 102.4 & 102.2 \\
\hline
\end{tabular}

Molecular structure and electronic charge distributions are determined by different interactions within molecule and their possible modifications with surrounding molecule interactions. Different semi-empirical and ab-initio methods such as Hartree-Fock (HF) method and DFT/B3LYP combined with different bases are very often used for study of different properties of molecule [19, 20, 21]. DFT/B3LYP method has proved to be a powerful tool with high accuracy in reproduction of experimental values of molecular geometry, vibrational frequencies, atomic charges, polar moments, thermodynamic properties [22, 23, 24]. Using DFT/B3LYP6-311G(d,p) method, we predict values of geometry parameters such as valence angles and bond lengths of 4,4-dimethyl-3,4-dihydroquinoline-2(1H)-one derivatives. Values of bond lengths and valence angles of structures studied vary very little from one derivative to another. Substituents in positions 5 and 8 have very little influence on these geometrical parameters. Apart from bonds $\mathrm{N} 1-\mathrm{C} 2, \mathrm{C} 2=\mathrm{O} 11, \mathrm{~N} 1-\mathrm{H} 12$ and $\mathrm{O} 11-\mathrm{H} 12$ which undergo modification in structures of transitions states, values of other bonds lengths are substantially same for structures of tautomers and transition states. Bond N1-C2 increases by $0.05 \AA$ and bond $\mathrm{C} 2=011$ decreases by about $0.06 \AA$ in transition state structures. These two bonds evolve respectively towards formation of single and double bond to give tautomer enol. Hydrogen atom is substantially equidistant from heteroatoms $\mathrm{N}$ and $\mathrm{O}$ in transition state $(\mathrm{N} 1$ $\mathrm{H} 12=1.36 \AA$ and $\mathrm{O} 11-\mathrm{H} 12=1.34 \AA$ ).

\subsection{Dipole Moment and Polarizability}

Nonlinear optical response of an isolated molecule in an electric field $\operatorname{Ei}(x)$ can be represented by a Taylor series development of total dipole moment $\mu_{t o t}$ according to the following relation:

$$
\mu_{t o t}=\mu_{o}+\alpha_{i j} E_{j}+\beta_{i j k} E_{j k}+\ldots
$$

Where $\alpha$ is linear polarizability, $\mu_{o}$ is permanent dipole moment and $\beta_{i j k}$ are first constituents hyperpolarizability tensor. Parameters analyzed in this work are dipole moment and linear polarizability $(\alpha)$ of tautomers ketone. The polarizability $(\alpha)$ is calculated from the relation below [25]:

$$
\alpha_{t o t}=\frac{1}{3}\left(\alpha_{x x}+\alpha_{y y}+\alpha_{z z}\right)
$$

Values of polarizability $(\alpha)$ of Gaussian 03 output files are in atomic units (au.). These values are converted into electrostatic units (esu) ( $\left.1 \mathrm{au}=0.1482 \times 10^{-24} \mathrm{esu}\right)$. Dipole moment and polarizability of DdQ-2 derivative in DMF are 7.4040 Debye and $31.900 .10^{-24}$ esu respectively solvent. Value of dipole moment of DdQ-2 derivative is approximately twice as high compared to that of DdQ-1 and DdQ-3 derivatives. Polarizability values of substituted derivatives are greater than that of unsubstituted molecule (DdQ-1). Derivative DdQ-3 has the largest value of polarizability. Methoxyl group $(\mathrm{CH} 3 \mathrm{O})$ and bromine atom 
(Br) influence polarity $(\mu)$ and polarizability $(\alpha)$ of quinoline-2-one. These results show that methoxyl group increases dipole moment of quinoline-2-one. Bromine atom decreases polarity of quinoline-2-one while methoxyl group increases it.

Table 3. Dipole moments (Debye) and polarizabilities (esu) of tautomers ketone calculated at B3LYP/6-311G(d,p) level.

\begin{tabular}{lllllll}
\hline \multirow{2}{*}{ Molecules } & \multicolumn{2}{l}{ Gas phase } & & \multicolumn{3}{l}{ DMF solvent } \\
\cline { 2 - 6 } & $\boldsymbol{\mu}$ & $\boldsymbol{\alpha}(\mathbf{u a})$ & $\boldsymbol{\alpha . 1 0}^{-24}$ (esu) & $\boldsymbol{\mu}$ & $\boldsymbol{\alpha}(\mathbf{u a})$ \\
\hline DTQ-1 & 3.027 & 125.803333 & 18.644 & 3.913 & 169.428667 \\
DTQ-2 & 5.639 & 161.842333 & 23.985 & 7.404 & 25.109 \\
DTQ-3 & 2.569 & 163.838667 & 24.281 & 3.334 & 31.900 & 223.729333 \\
\hline
\end{tabular}

\subsection{HOMO-LUMO Analysis}

Energetic gap (HOMO-LUMO) plays a very important role in determining chemical reactivity, stability of molecule, UV-Vis spectra, chemical reactions, electrical and optical properties [26]. LUMO energy means ability to accept an electron while HOMO energy means ability to donate an electron. Chemical reactivity of a molecule can be determined from HOMO-LUMO energy gap. A small gap implies low kinetic stability of molecule. Frontier molecular orbital can offer a reasonable qualitative prediction of excitation properties and ability of electron transport. Energetic gap, energies of HOMO and LUMO orbitals and reactivity parameters $\left(n, \omega^{-}, \omega^{+}\right)$of tautomers are reported in table 4.

Tautomers enol have higher energetic gap values than corresponding ketone tautomers. Substituted derivatives have smaller energetic gap values than unsubstituted tautomer (DdQ-1). Brominated derivative has smallest energetic gap value. It is therefore the most reactive derivative. Bromine atom helps to increase reactivity of quinolines. Previous work on reactivity of quinolein-4-one derivatives has also revealed that bromine atom $(\mathrm{Br})$ increases reactivity of quinoline-4-one [13]. Electron-withdrawing substituents increase reactivity of quinoline-2-one.

For understanding various aspects of molecular reactivity, several new chemical reactivity descriptors have been proposed. Conceptual DFT based descriptors have helped in many ways to understand structure of molecules and their reactivity by calculating certain reactivties parameters such as chemical potential, global hardness and electrophilicity. Using HOMO and LUMO orbital energies, ionization energy and electron affinity can be expressed as: $\mathrm{I}=-\varepsilon_{\mathrm{HOMO}}, \mathrm{A}=-$ $\varepsilon_{\mathrm{LUMO}}$, hardness is given by following relation: $\eta=\frac{(I-A)}{2}$ and $\mu=-\frac{(I+A)}{2}$ It contains information about both electron transfer (chemical potential) and stability (hardness) and is a better descriptor of global chemical reactivity.

Ectron-acceptor $\left(\omega^{+}\right)$and electron-donor $\left(\omega^{-}\right)$powers [27] are calculated from equations below:

$$
\begin{aligned}
& \omega^{+}=\frac{(I+3 A)^{2}}{16(I-A)} \\
& \omega^{-}=\frac{(3 I+A)^{2}}{16(I-A)}
\end{aligned}
$$

These reactivity parameters measure respectively ability of molecule to accept electrons and ability of molecule to donate electrons.

Tautomers enol have lowest values of chemical hardness (n). These are most reactive. For all tautomers, values of $\omega^{-}$ are much higher than those of $\omega^{+}$. Molecules studied all have an electro-electron donor character. Values of $\omega^{-}$of tautomers enol decrease compared to values obtained with ketone tautomers. Derivatives DdQ-2 and DdQ-3 have values of $\omega$ the lowest compared to value obtained with derivative DdQ1. Substituents on quinoline-2-one decrease electro-electron donor character of quinoline-2-one.

Table 4. Energetic gap (eV), HOMO and LUMO orbitals energies (eV), hardness $(\mathrm{eV})$, electron-acceptor $\left(\omega^{+}\right)$and electron-donor $\left(\omega^{-}\right)$powers $(\mathrm{eV})$ of tautomers calculated at B3LYP/6-311G(d,p) level in DMF solvent.

\begin{tabular}{lllllll}
\hline Tautomers & $\boldsymbol{\varepsilon}_{\text {номо }}$ & $\boldsymbol{\varepsilon}_{\text {LUMo }}$ & $\boldsymbol{\Delta} \mathbf{E}$ & $\boldsymbol{\eta}$ & $\boldsymbol{\omega}^{-}$ & $\boldsymbol{\omega}^{+}$ \\
\hline DTQ-1 & -5.95 & -0.88 & 5.07 & 6.83 & 4.32 & 0.91 \\
DTQ-1-ol & -5.68 & -0.71 & 4.98 & 6.39 & 3.96 & 0.77 \\
DTQ-2 & -5.57 & -0.63 & 4.94 & 6.20 & 3.80 & 0.70 \\
DTQ-2-ol & -5.27 & -0.65 & 4.65 & 5.92 & 3.67 & 0.71 \\
DTQ-3 & -5.43 & -0.63 & 4.80 & 6.06 & 3.73 & 0.70 \\
DTQ-3-ol & -5.35 & -0.61 & 4.71 & 5.96 & 3.66 & 0.68 \\
\hline
\end{tabular}

\subsection{Local Reactivity Indices}

Fukui indices $f(r)^{+}$and $f(r)^{-}$have been considered to describe site selectivity or reactivity of an atom $\mathrm{k}$ in a molecule [28]. This latter can be realized by electronic population analysis.

$$
\begin{gathered}
f(r)^{+}=\mathrm{q}(\mathrm{N}+1)-\mathrm{q}(\mathrm{N}) \\
f(r)^{-}=\mathrm{q}(\mathrm{N})-\mathrm{q}(\mathrm{N}-1) \\
\Delta f(r)=f_{k}^{+}(r)-f_{k}^{-}(r)
\end{gathered}
$$

$\mathrm{q}_{\mathrm{k}}(\mathrm{N}), \mathrm{q}_{\mathrm{k}}(\mathrm{N}-1)$ and $\mathrm{q}_{\mathrm{k}}(\mathrm{N}+1)$ atomic is charges sites $\mathrm{k}$ in neutral, cationic and anionic systems, respectively.

$\Delta \mathrm{f}$ is a function which represents reactivity of molecule. The positive or negative value of this function indicates respectively an electrophilic zone or a nucleophilic zone.

It should be noted that the high reactivity of quinoline derivatives is linked to fact that these molecules have several reaction sites. It is therefore useful to determine interaction sites (nucleophilic and electrophilic) of this derivatives. Fukui indices calculations are necessary to identify these interaction sites. Calculation of these indices was performed using Hirschfeld [29] populations on ketone tautomers (DdQ- 
1, DdQ-2 and DdQ-3). which are found to be the most stable. Results of these calculations are summarized in Table 5. Atoms concerned in this study are atoms of quinoline-2-one ring (Figure 1).

A positive value of $\Delta f(r)$ indicates an electrophilic region. A nucleophilic site gives a negative value of $\Delta f(r)$. In all derivatives concerned by this analysis, this reactivity parameter has a positive value at level of tatoms $C^{2}, C^{3}, C^{5}$, $\mathrm{C}^{7}, \mathrm{C}^{8}$ et $\mathrm{C}^{10}$ (Table 6). These atoms are electrophilic sites. A nucleophilic attack would probably occur at these atoms. carbons $\mathrm{C}^{2}$ and $\mathrm{C}^{5}$ have the highest values of $\Delta f(r)$. These would be more reactive vis-à-vis a nucleophilic attack. Atoms $\mathrm{N}^{1}, \mathrm{C}^{4}, \mathrm{C}^{6}, \mathrm{C}^{9}$ and $\mathrm{O}^{11}$ have values of $\Delta f(r)$ negative. These atoms are therefore nucleophilic sites. Nitrogen $\mathrm{N}^{3}$ has lowest value of $\Delta f(r)$ and the maximum value of $f(\mathrm{r})$ in derivatives, DdQ-2 and DdQ-3. An electrophilic attack of these derivatives would be done prioritarily on this atom $\left(\mathrm{N}^{3}\right)$. Quinolein-2-one derivatives studied have same electrophilic and nucleophilic sites. Methoxyl $\left(\mathrm{CH}_{3} \mathrm{O}\right)$ and Bromine (Br) Substituents do not modify sites of interaction in these molecules.

Table 5. Local reactivity indices calculated at $B 3 L Y P / 6-311+G(d, p)$ level in gas phase.

\begin{tabular}{|c|c|c|c|c|c|c|c|c|c|}
\hline \multirow{2}{*}{ Atoms } & \multicolumn{3}{|l|}{ DTQ-1 } & \multicolumn{3}{|l|}{ DTQ-2 } & \multicolumn{3}{|l|}{ DTQ-3 } \\
\hline & $f^{+}$ & $f$ & $\Delta f$ & $f^{+}$ & $f$ & $\Delta f$ & $f^{+}$ & $f$ & $\Delta f$ \\
\hline $\mathrm{N}^{1}$ & -0.064 & 0.13 & -0.194 & -0.061 & 0.203 & -0.264 & -0.075 & 0.186 & -0.261 \\
\hline$C^{2}$ & 0.083 & -0.019 & 0.102 & 0.085 & -0.034 & 0.119 & 0.087 & -0.025 & 0.112 \\
\hline $\mathrm{C}^{3}$ & 0.080 & -0.014 & 0.094 & 0.057 & -0.025 & 0.082 & 0.058 & -0.031 & 0.089 \\
\hline $\mathrm{C}^{4}$ & -0.065 & 0.104 & -0.169 & -0.069 & 0.105 & -0.174 & -0.051 & 0.122 & -0.173 \\
\hline $\mathrm{C}^{5}$ & 0.117 & -0.021 & 0.138 & 0.109 & -0.034 & 0.143 & 0.114 & -0.035 & 0.149 \\
\hline $\mathrm{C}^{6}$ & -0.019 & 0.085 & -0.104 & -0.026 & 0.090 & -0.116 & -0.018 & 0.102 & -0.120 \\
\hline$C^{8}$ & 0.085 & -0.006 & 0.091 & 0.100 & -0.002 & 0.102 & 0.085 & -0.019 & 0.104 \\
\hline $\mathrm{C}^{9}$ & -0.054 & 0.014 & -0.068 & -0.032 & 0.022 & -0.054 & -0.036 & 0.022 & -0.058 \\
\hline $\mathrm{C}^{10}$ & 0.031 & -0.024 & 0.055 & 0.036 & -0.028 & 0.064 & 0.042 & -0.037 & 0.079 \\
\hline $\mathrm{O}^{11}$ & -0.025 & 0.186 & -0.211 & -0.041 & 0.175 & -0.216 & -0.058 & 0.169 & -0.227 \\
\hline
\end{tabular}

\subsection{Prediction of Acidity}

Deprotonation energies are widely used for prediction of Brönsted acidity in gaseous and aqueous phases [30, 31]. Deprotonation reaction is defined by following relationship:

$$
A H \rightarrow A^{-}+H^{+}
$$

Gibbs energy $\Delta G$ of protonic abstraction reaction is as follows:

$$
\Delta G=\Delta H-T \Delta S
$$

Contribution of entropy is given by the expression below:

$$
-T \Delta S=-T\left[S\left(A^{-}\right)+S\left(H^{+}\right)-S(A H)\right]
$$

For temperature of $\mathrm{T}=298 \mathrm{~K}$ at standard pressure, $T S\left(H^{+}\right)=32.5 \mathrm{~kJ} \cdot \mathrm{mol}^{-1}[30,31]$, gives expression follows:

$$
\Delta G=\Delta_{f} G\left(A^{-}\right)-\Delta_{f} G(A H)-32.5
$$

Previous theoretical work on prediction of acidity has shown that the hybrid functionals such as B3LYP associated with bases $6-311+\mathrm{G}(\mathrm{d}), 6-311+\mathrm{G}(\mathrm{d}, \mathrm{p}), 6-311+\mathrm{G}(3 \mathrm{df}, 3 \mathrm{pd})$ lead to results in good agreement with experimental data [32, $33,34]$. This motivates the choice of level of calculation implemented in this work. Free energies of deprotonation $(\Delta G)$ are calculated in gas phase at B3LYP/6-311+G(d) level. Values of this thermodynamic quantity are reported in

\begin{tabular}{|c|c|c|c|}
\hline \multirow[b]{2}{*}{ Tautomers } & \multicolumn{2}{|l|}{$\Delta_{f} G$ (ua) } & \multirow{2}{*}{$\begin{array}{l}\Delta G \\
\left.\left(K_{c a l . m o l}\right)^{1}\right)\end{array}$} \\
\hline & $\boldsymbol{A H}$ & $\begin{array}{l}\text { Deprotonated } \\
\text { molecule } A^{-}\end{array}$ & \\
\hline DdQ-1 $\left(\mathrm{N}^{1}-\mathrm{H}^{12}\right)$ & -556.958633 & -556.40628 & 339.0 \\
\hline DdQ-1-ol $\left(\mathrm{O}^{11}-\mathrm{H}^{12}\right)$ & -556.936526 & -556.456281 & 293.7 \\
\hline DdQ-2( $\left.\left(\mathrm{N}^{1}-\mathrm{H}^{12}\right)\right)$ & -786.001995 & -785.469585 & 326.4 \\
\hline DdQ-2-ol $\left(\mathrm{O}^{11}-\mathrm{H}^{12}\right)$ & -785.974386 & -785.489586 & 296.6 \\
\hline DdQ-3( $\left.\left.\mathrm{N}^{1}-\mathrm{H}^{12}\right)\right)$ & -5704.058757 & -5703.551983 & 310.4 \\
\hline DdQ-3-ol $\left(\mathrm{O}^{11}-\mathrm{H}^{12}\right)$ & -5704.036915 & -5703.581981 & 277.8 \\
\hline
\end{tabular}
table 6.
Table 6. Free enthalpies of formation and deprotonation of quinoline-2-one tautomers calculated at B3LYP/6-311+G(d,p) level in gas phase.

Data grouped in Table 6 show a decrease in the free enthalpy of deportation reaction with substituted derivatives (DdQ-2 et DdQ-3). On basis of free energies of deprotonation of molecules studied, one can establish the increasing order of deprotonation as follows:

$$
\begin{gathered}
\Delta \mathrm{G}\left[\mathrm{DdQ}-3-\mathrm{ol}\left(\mathrm{O}^{11}-\mathrm{H}^{12}\right)\right]<\Delta \mathrm{G}\left[\mathrm{DdQ}-2-\mathrm{ol}\left(\mathrm{O}^{11}-\mathrm{H}^{12}\right)\right]< \\
\Delta \mathrm{G}\left[\mathrm{DdQ}-1\left(\mathrm{O}^{11}-\mathrm{H}^{12}\right)\right]<\Delta \mathrm{G}\left[\mathrm{DdQ}-3\left(\mathrm{~N}^{1}-\mathrm{H}^{12}\right)\right]<\Delta \mathrm{G}[\mathrm{DdQ}- \\
\left.2\left(\mathrm{~N}^{1}-\mathrm{H}^{12}\right)\right]<\Delta \mathrm{G}\left[\mathrm{DdQ}\left(\mathrm{N}^{1}-\mathrm{H}^{12}\right)\right]
\end{gathered}
$$

For a given quinoline, deprotonation energy of hydroxyl $\left(\mathrm{O}^{11}-\mathrm{H}^{12}\right)$ of tautomer enol is lower than that of the nitrogen (N1-H) of tautomer ketone. Energies of free enthalpy of deprotonation are lower with tautomers enol. Bromine and methoxyl group contributes to reducing free energies of deprotonation of the nitrogen $\left(\mathrm{N}^{1}\right)$ and oxygen $\left(\mathrm{O}^{11}\right)$ atoms. This thermodynamic quantity decreases by $12.6 \mathrm{Kcal}^{\mathrm{mol}}{ }^{-1}$ and $28.6 \mathrm{Kcal}^{\mathrm{mol}} \mathrm{l}^{-1}$ respectively with derivatives DdQ-2 and DdQ-3. These results indicate that a deprotonation of $\mathrm{N}^{1}-\mathrm{H}^{12}$ nitrogen in case of quinolin-2-one brominated will be easier than that of nitrogen $\left(\mathrm{N}^{1}-\mathrm{H}^{12}\right)$ of derivative methoxylated. Work has shown that there is an inverse relationship between 
the amplitude of $\Delta \mathrm{G}$ and the strength of the acid. The lower the value of $\Delta \mathrm{G}$, the more acidic the site is $[30,31]$. In this way, nitrogen atoms $\mathrm{N}^{1}-\mathrm{H}^{12}$ and oxygen $\mathrm{O}^{11}-\mathrm{H}^{12}$ in compounds brominated are more acidic. These sites are less acidic in derivatives methoxylated. Through analysis of these free energies of deprotonation, we can establish the following decreasing order of acidity of sites $\mathrm{N}^{1}$ and $\mathrm{O}^{11}$ of tautomers ketone:

$$
\begin{gathered}
\text { DdQ-3-ol }\left(\mathrm{O}^{11}-\mathrm{H}^{12}\right)>\operatorname{DdQ}-2-\mathrm{ol}\left(\mathrm{O}^{11}-\mathrm{H}^{12}\right)>\operatorname{DdQ}-1\left(\mathrm{O}^{11}-\mathrm{H}^{12}\right)> \\
\text { DdQ-3 }\left(\mathrm{N}^{1}-\mathrm{H}^{12}\right)>\operatorname{DdQ}-2\left(\mathrm{~N}^{1}-\mathrm{H}^{12}\right)>\operatorname{DdQ}-1\left(\mathrm{~N}^{1}-\mathrm{H}^{12}\right)
\end{gathered}
$$

\section{Conclusion}

This theoretical study concerns stability, reaction mechanism of tautomeric equilibrium and acidity of tautomers of 4,4-Dimethyl-3,4-dihydro-quinolin-2(1H) -one Derivatives derivatives. it relies on elaborate methods of theoretical chemistry to take stock of reactivity of its tautomeric forms and the acidity of its heteroatoms. Calculation of equilibrium constants confirms existence of tautomeric equilibrium. Study of reaction mechanism of this tautomeric equilibrium revealed nonexistence of an intermediate reaction product. Thermodynamic data show that tautomers keton eare more stable than tautomers enol. This tautomeric equilibrium reaction is an endothermic reaction. Reactivity analysis based on theory of frontier molecular orbitals has shown that methoxyl $\left(\mathrm{CH}_{3} \mathrm{O}\right)$ and bromine $(\mathrm{Br})$ substituents increase reactivity of quinoline-2one. Brominated derivatives are more reactive than the methoxylated analogs. Also these results show that methoxyl group increases dipole moment of quinoline-2-one while the bromine atom contributes to increase polarizability of this molecule. Calculation of Fukui functions identified interaction sites of 4,4-dimethyl-3,4-dihydroquinoline-2-one ring. Carbon atoms $\mathrm{C}^{2}, \mathrm{C}^{3}, \mathrm{C}^{5}, \mathrm{C}^{7}$ and $\mathrm{C}^{8}$ are electrophilic sites and $\mathrm{N}^{1}, \mathrm{C}^{4}, \mathrm{C}^{6}$ and $\mathrm{O}^{11}$ are nucleophilic sites. Results predict a higher acidity of $\mathrm{N} 1-\mathrm{H}$ and $\mathrm{O} 11-\mathrm{H}$ sites of brominated derivatives.

\section{Acknowledgements}

Thanks to the colleagues of Organic Chemistry and Natural Substances laboratory of University Felix Houphouët Boigny for their advice.

\section{References}

[1] L. M. Nainwal, S. Tasneem, W. Akhtar, G. Verma, M. F. Khan, S. Parvez, M. Shaquiquzzaman, M. Akhter and M. M. Alam, Eur. J. Med. Chem., 2019, 164, 121-170.

[2] H. S. Soor, S. D. Appavoo and A. K. Yudin, Bioorg. Med. Chem., 2019, 26, 10, 2774-2779.

[3] A. Detsi, D. Bouloumbasi, K. C. Prousis, M. Koufaki, Athanasellis G., Melagraki G., A. Afantitis, O. IgglessiMarkopoulou, C. Kontogiorgis and D. J. Hadjipavlou-Litina, J. Med. Chem., 2007, 50, 2450-2458.
[4] M. Akranth, O. P. Tanwar, R. Saha, A. M. Rahmat, S. Srivastava, M. Akhter, M. Shaquiquzzaman and M. M. Alam, Saudi Pharm. J., 2013, 21, 1, 1-12.

[5] K. Kaur, M. Jain, R. P. Reddy and R. Jain, Eur. J. Med. Chem., 2010, 45, 8, 3245-3264.

[6] M. C. Mandewale, U. C. Patil, S. V. Shedge, U. R. Dappadwad, R. S. Yamgar, / Beni-Suef Univ. J. Basic Appl. Sci., 2017, 6, 4, 354-361.

[7] T. G. Shruthi, S. Eswaran, P. Shivarudraiah, S. Narayanan and S. Subramanian, Bioorg. Med. Chem. Lett., 2019, 29, 1, $97-$ 102.

[8] P. Tenga, C. Lib, Z. Pengb, A. M. Vanderschouw, A. Nimmagadda, M. Su, Y. Li, J. X. S. Cai, Bioorg. Med. Chem., 2018, 26, 12, 3573-3579.

[9] J. Zhang, W. Su, Y. Ba and Z. Xu, Eur. J. Med. Chem., 2019, $174,1-8$.

[10] F. Saccoliti, V. N. Madia, V. Tudino, A. De Leo, L. Pescatori, A. Messore, D. De Vita, L. Scipione, R. Brun, M. Kaiser, P Mäser, C. M. Calvet, G. K. Jennings, L. M. Podust, R. Costi, R. Di Santo, Eur. J. Med. Chem., 2018, 2018, 156, 53-60.

[11] O. Afzal, S. Kumar, M. R. Haider, M. R. Ali, R. Kumar, M. Jaggi and S. Bawa, Eur. J. Med. Chem., 2015, 97, 871-910.

[12] A. H. Abadi, G. H. Hegazy and A. A E. Zaher, Bioorg. Med. Chem., 2005, 13, 5759-5765.

[13] A. L. Bédé., A. B. Assoma, K. D. Yapo, M. G. R. Koné, S. Koné, M. Koné, B. R. N'Guessan and E. H. S. Bamba, Computational Chemistry, 2018, 6, 57-70.

[14] M. J. Frisch, G. W. Trucks, H. B. Schlegel, and al. Gaussian Inc. Pittsburgh. 2003.

[15] A. D. Becke, J. Chem. Phys. 1993, 98, 7, 5648-5652.

[16] Sébastien Bouclé; Synthèse D'analogues d'Alcaloïdes Marins à Potentiel Anti-Tumoral. Thèse de Doctorat, Université Francois-Rabelais de Tours, 3 Décembre 2010. http://www.applis.univtours.fr/theses/2010/sebastien.boucle_3490.pdf

[17] C. Gonzalez and H. B. Schlegel, Journal of Physical Chemistry, 1990, 94, 14, 5523-5527.

[18] H. Eyring, Chemical Reviews, 1935, 17, 1, 65-77.

[19] A. D. Boese and J. Sauer, Cryst. Growth Des., 2017, 17, 4, 1636-1646.

[20] A. L. Bédé, A. B. Assoma, E. H. S. Bamba, M. Dan and I. Humelnicu, J. Mater. Phys. Chem., 2018, 6, 1, 17-22.

[21] Y. Minenkov and L. Cavallo, ACS Omega, 2017, 2, 11, 83738387.

[22] G. S. Kurkcuoğlu, E. Sayın, K. Gor, T. Arslan and O. Buyukgungor, Vibritional Spectroscopy, 2014, 71, 105.

[23] E. Temel, C. Alasalvar, H. Gokce, A. Guder, C. Albayrak, Y. A. Bingol, Alpaslan G and N. Dilek, Spectrochim. Acta, Part A, 2015, 136, 534-546.

[24] U. Ceylan, G. O. Tarı, H. Gokce and E. Ağar, J. Mol. Struct., 2016, 1110, 1-10.

[25] T. Rajamani, and S. Muthu, Solid State Sci., 2013, 16, 90-101. 
[26] A. Jun-ichi, J. Phys. Chem. A, 1999, 103 (37), 7487-7495.

[27] J. L. Gazquez, A. Cedillo and A. Vela, J. Phys. Chem. A, 2007, 111, 1966-1970.

[28] K. Harrath, S. Boughdiri, R. Linguerri and M. Hochlaf, Theor. Chem. Acc., 2016, 2, 135-144.

[29] R. K. Roy, S. Pal and K. Hirao, J. Chem. Phys., 1999, 110, 17, 8236-8245.

[30] I. A. Topol, G. J. Tawa, S. K. Burt and A. A. Rashin, J. Phys. Chem. A, 1997, 101, 51, 10075-10081.
[31] M. Remko, J. Phys. Chem. A, 2003, 107 (5), 720-725.

[32] J. A. Keith and E. A. Carter, J. Chem. Theory Comput., 2012, $8,9,3187-3206$.

[33] M. Remko and C. W. von der Lieth, Bioorg. Med. Chem., 2004, 12, 20, 5395-5403.

[34] R. Vianello and Z. B. Maksić, Tetrahedron Lett., 2005, 46, 21, 3711-3713. 